\title{
Environmental impacts of future urban deployment of electric vehicles: Assessment framework and case study of Copenhagen for 2016-2030
}

Bohnes, Florence Alexia; Gregg, Jay Sterling; Laurent, Alexis

Published in:

Environmental Science and Technology

Link to article, DOI:

10.1021/acs.est.7b01780

Publication date:

2017

Document Version

Peer reviewed version

Link back to DTU Orbit

Citation (APA):

Bohnes, F. A., Gregg, J. S., \& Laurent, A. (2017). Environmental impacts of future urban deployment of electric vehicles: Assessment framework and case study of Copenhagen for 2016-2030. Environmental Science and Technology, 51(23), 13995-14005. https://doi.org/10.1021/acs.est.7b01780

\section{General rights}

Copyright and moral rights for the publications made accessible in the public portal are retained by the authors and/or other copyright owners and it is a condition of accessing publications that users recognise and abide by the legal requirements associated with these rights.

- Users may download and print one copy of any publication from the public portal for the purpose of private study or research.

- You may not further distribute the material or use it for any profit-making activity or commercial gain

- You may freely distribute the URL identifying the publication in the public portal 


\section{Article}

Subscriber access provided by DTU Library

Environmental impacts of future urban deployment of electric vehicles: Assessment framework and case study of Copenhagen for 2016-2030

Florence Alexia Bohnes, Jay Sterling Gregg, and Alexis Laurent

Environ. Sci. Technol., Just Accepted Manuscript • DOI: 10.1021/acs.est.7b01780 • Publication Date (Web): 09 Nov 2017

Downloaded from http://pubs.acs.org on November 13, 2017

\section{Just Accepted}

"Just Accepted" manuscripts have been peer-reviewed and accepted for publication. They are posted online prior to technical editing, formatting for publication and author proofing. The American Chemical Society provides "Just Accepted" as a free service to the research community to expedite the dissemination of scientific material as soon as possible after acceptance. "Just Accepted" manuscripts appear in full in PDF format accompanied by an HTML abstract. "Just Accepted" manuscripts have been fully peer reviewed, but should not be considered the official version of record. They are accessible to all readers and citable by the Digital Object Identifier (DOI®). "Just Accepted" is an optional service offered to authors. Therefore, the "Just Accepted" Web site may not include all articles that will be published in the journal. After a manuscript is technically edited and formatted, it will be removed from the "Just Accepted" Web site and published as an ASAP article. Note that technical editing may introduce minor changes to the manuscript text and/or graphics which could affect content, and all legal disclaimers and ethical guidelines that apply to the journal pertain. ACS cannot be held responsible for errors or consequences arising from the use of information contained in these "Just Accepted" manuscripts. 


\section{Environmental impacts of future urban deployment of electric vehicles:}

\section{Assessment framework and case study of Copenhagen for 2016-2030}

3

4

5

6 a: Division for Quantitative Sustainability Assessment (QSA), Department of Management Engineering, 7 Technical University of Denmark, 2800 Kgs. Lyngby, Denmark.

8 b: Division for System Analysis (SYS), Department of Management Engineering, Technical University of 9 Denmark, 2800 Kgs. Lyngby, Denmark.

10

$11 *$ To whom correspondence should be addressed; e-mail: flbo@dtu.dk; postal address: DTU Management 12 Engineering, Bygningstorvet, Building 116B, Room 104A, 2800 Kgs. Lyngby (DENMARK). 
14

\section{Abstract}

To move towards environmentally-sustainable transport systems, electric vehicles (EVs) are increasingly seen as viable alternatives to internal combustion vehicles (ICVs). To ensure effectiveness of such deployment, holistic assessments of environmental impacts can help decision-makers determine optimized urban strategies in a long-term perspective. However, explicit guidance and conduct of such assessments are currently missing. Here, we therefore propose a framework using life cycle assessment that enables the quantification of environmental impacts of a transport system at full urban scale from a fleetbased, foresight perspective. The analysis of the passenger car fleet development in the city of Copenhagen for the years 2016-2030 is used as a proof-of-concept. We modeled and compared five powertrain technologies, and we assessed four fleet-based scenarios for the entire city. Our results showed relative environmental benefits from range-extended and fuel-cell EVs over ICVs and standard EVs. These results were found to be sensitive to local settings, like electricity grid mix, which could alter the relative environmental performances across EV technologies. The comprehensive framework developed here can be applied to other geographic areas and contexts to assess the environmental sustainability of transport systems. 


\section{Introduction}

Following the recent advancements in electric vehicle technologies, transport systems have entered a transition period ${ }^{1}$. New policy strategies toward e-mobility, i.e. the increasing use of electric vehicles (EVs) for transport purposes, have for example been adopted in Europe $e^{2,3}$, and urban development aiming to encourage such a change have started $^{4}$. Internal combustion engine vehicles (ICVs) are important contributors to climate change $\mathrm{e}^{5}$ and local air pollution ${ }^{6}$ and some authors have suggested that such a transition has the potential to reduce environmental impacts and resource depletion ${ }^{7,8}$. Indeed, these technologies entail little or no direct tailpipe emissions of greenhouse gases (GHG) and the engines are more energy efficient than internal combustion engines ${ }^{9}$. Nevertheless, there are impacts associated with EVs during their manufacturing and disposal as well as from the indirect emissions at power plants ${ }^{10}$. Because electricity is often produced from coal, alternative vehicles technologies may also be associated with large environmental and health impacts. Only looking at the direct emissions and impacts during the use of these vehicles in decision-making processes (e.g. for eco-design purposes or e-mobility urban development) may therefore distort the picture and result in environmental burden-shifting from the use stage, where EVs may be associated with low impacts, to other stages of the vehicle life cycle, such as the extraction of the necessary raw materials, the manufacturing of the vehicle and/or its end-of-life. Therefore, decision-makers need holistic impact assessment tools to consistently decide how to develop or enhance the electric fleet at urban scale and specifically target part of the transport systems for environmental improvements.

Life cycle assessment (LCA) can be used to comprehensively address these risks and identify when and where environmental burden-shifting occurs. LCA is an internationally-standardized methodology used to inventorise emissions and resource consumption of a product or a system in a life cycle perspective and subsequently assess their related impacts on human health, ecosystems and natural resources ${ }^{11,12}$. By covering the entire life cycle of the analyzed system and the broad range of environmental impacts, LCA can reduce the risk of burden-shifting when moving towards new technologies or systems ${ }^{13}$.

Though LCA has been intensively used to assess the environmental impacts of EVs, previous reviews have highlighted a low compliance with LCA methodological guidelines ${ }^{14,15}$ and a lack of transparency in the inventories. ${ }^{16,17}$ Moreover, the inclusion of a future-oriented perspective have only been addressed in few past studies ${ }^{18,19}$ while there is an increasing need for quantitatively anticipating the 
environmental impacts of the implementation of future policies, which require combining environmental impact assessment tools and simulations of scenarios over long periods of time $\mathrm{e}^{20,21}$. Additionally, although LCA has been primarily developed as product oriented, Field et al. ${ }^{22}$ demonstrated that fleet-based LCA is preferred in a majority of sectors since it allows a thorough perspective of the comparative emissions burdens and reduces the simplifying assumptions inherent in analyzing a single product. Several authors have conducted studies on the deployment of EVs in current and future fleets (e.g. refs. ${ }^{23-32}$ ). However, these assessments are often limited in that they (i) have a limited impact coverage (typically centered on climate change and energy demand), ${ }^{24-27}$ (ii) have a narrow technological scope that covers only a few EV technologies (often only hybrid and battery electric vehicles), ${ }^{23,25,28}$ (iii) do not embrace an all-inclusive fleetbased perspective, thus leaving out parts of the system (e.g. charging infrastructures), ${ }^{29-31}$ or (iv) do not encompass a future-oriented perspective. ${ }^{32}$ To the knowledge of the authors, no studies have addressed all 4 limitations and investigated a large panel of technologies in a complete, foresight fleet-based assessment with a large impact coverage. ${ }^{16,17,33}$ In the context of urban transport planning, such limitations undermine the reliability and relevance of the assessment results and the subsequent support provided to decision-makers.

In this setting, we therefore aim to: (1) develop a comprehensive framework for performing foresight fleet-based LCAs of a urban transportation system, which can accommodate several powertrain technologies and a large set of impact categories while following the ISO guidelines ${ }^{14,15}$ and show high transparency of the inventories; (2) apply that framework to the progressive deployment of EVs in Copenhagen over the period 2016-2030, which thus serves as both proof-of-concept and illustrative case study; and (3) provide recommendations to LCA practitioners for their future LCA applications in that field and information to electric transportation stakeholders. The municipality of Copenhagen has been chosen for its ambitious climate plan of being the first carbon neutral capital by 2025 and for its data availability ${ }^{34}$.

\section{Materials and methods}

\subsection{General framework}

We propose a generic framework and methodology to assess the life-cycle environmental impacts of an urban fleet, designed to be applicable on a specific city, over a certain period of time and for a defined type of vehicle. The different steps and data needs are synthesized in Figure 1 and they are described 
85

succinctly in the subsequent subsections (complemented with detailed documentation and guidance in Supporting Information (SI)). Each of the steps is also illustrated by the case study of passenger cars in Copenhagen over the period of time 2016-2030, which also serves as insight into the type of data required for the assessment.

The methodology includes two main stages: a vehicle-based LCA where the different powertrains selected for the study can be compared, thus giving an overview of the performances of individual vehicle technologies, and a fleet-based LCA, in which the vehicles, the charging infrastructures and the fuel and electricity production systems are assessed in their context taking into consideration the urban transport needs and the possible EV deployment scenarios over time. Both stages have a specific scope, functional unit and system boundaries and are conducted following the ISO 14040 and 14044 standards ${ }^{14,15}$.

\section{STEP 0: Focus of the study}

City $C$

Time-frame t1:t2 e.g. 2016-2030

Iypes of vehıcles $T \boldsymbol{V}$ (Passenger vehıcles, buses, trucks, etc)

STEP 1: SCope of the vehicle-based LCA
- Technologies of powertrains? Technologies $i$
- Functional unit FU_vehiche e.g. "Transport of $X X$ passengers (average) over $1 \mathrm{~km}$ by a private vehicle in average driving and meteorological conditions in
Copenhagen in either 2016 or $2030^{\prime \prime}$

Copenhagen in either 2016 or $2030^{\prime \prime}$

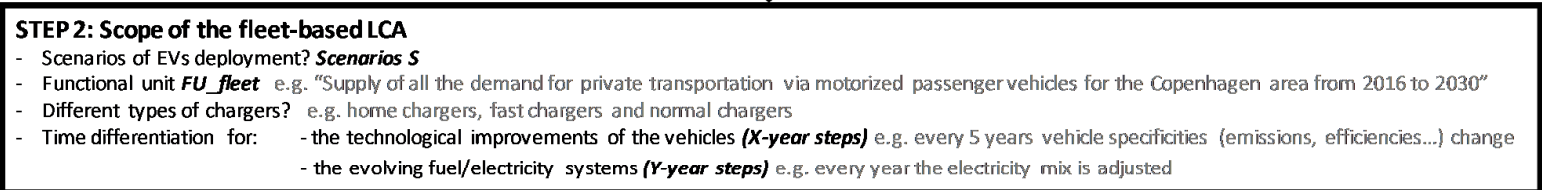

\section{2?}

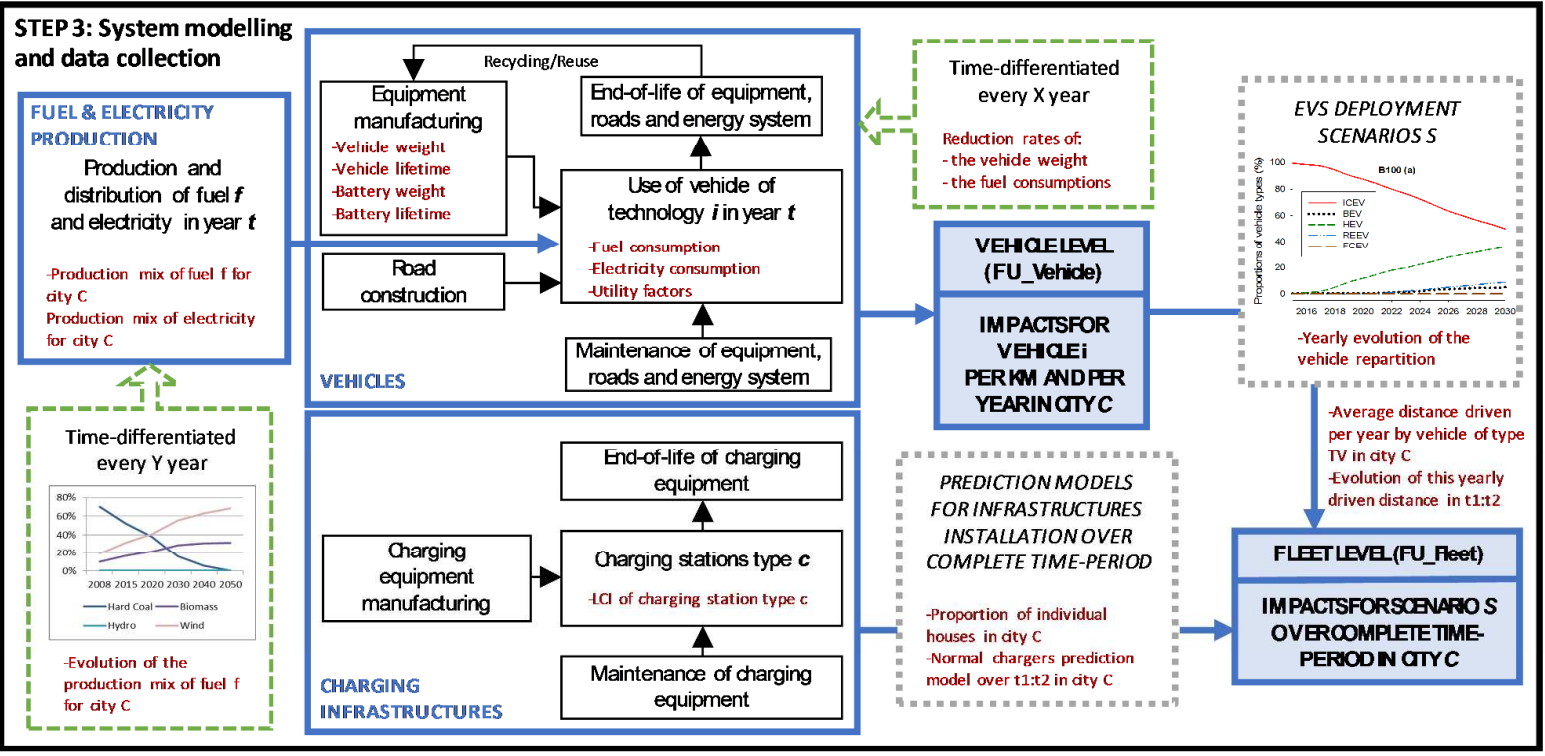

Figure 1: General framework of the methodology. Note that "Equipment manufacturing" implies extraction and processing of raw materials. Red text indicates data needs. Blue shaded boxes indicate the assessment results $($ FU_Vehicle $=$ functional unit at vehicle level \& FU_Fleet $=$ functional unit at fleet level). 


\subsection{Scoping of the vehicle-based LCA}

The technology landscape of passenger vehicles needs to be comprehensively modeled by considering a portfolio of powertrains as complete as possible, and corresponding to the city under study. For example, in the case of Copenhagen, five technologies of powertrains were considered: (1) ICVs, conventional vehicles powered by normal or optimized engines and driving on fossil fuels; (2) battery electric vehicles (BEVs), vehicles powered by an electric motor that carry a battery as energy storage; (3) hybrid electric vehicles (HEVs), vehicles powered by both an electric motor and a combustion engine (alternatively), and carry a battery (this includes plug-in HEVs (PHEVs), which charge their batteries from the electrical grid, and non-plug-in HEVs (nPHEVs), which charge their batteries from the combustion engine); (4) range-extended electric vehicles (REEVs), which are powered by an electric motor and carry a battery for principal energy storage but also have a combustion engine to extend the vehicle's range; and (5) fuel-cell electric vehicles (FCEVs), vehicles powered by an electric motor and carrying hydrogen fuel-cells for energy storage. Albeit not relevant for Copenhagen, other powertrains may additionally be considered, e.g. natural gas or biogas-based vehicles ${ }^{35}$.

To compare their environmental performances, a functional unit (FU), which quantifies the service or function the system provides and serves as basis for the comparisons, should be defined. Here it has been defined as "the transport of an average weight of passengers over $1 \mathrm{~km}$ by a private vehicle in average driving and meteorological conditions in Copenhagen in either 2016 or 2030". Such FU can easily be adapted to other settings in its current form. Including the entire life cycles of the vehicles (i.e. manufacturing, use, maintenance, and end-of-life), the fuels (i.e. well-to-wheel system for fossil fuels, electricity, or hydrogen) and the additional infrastructure (e.g. roads) ensure a comprehensive assessment ${ }^{16}$. In the present assessment at vehicle level, infrastructures associated with the charging systems and the hydrogen supply infrastructures were excluded as deemed of negligible impact (confirmed in the results; see Section 4.3).

\subsection{Scoping of the fleet-based LCA}

The fleet-based LCA is developed based on different deployment scenarios. The developed framework require to (i) obtain data on the transport needs in the given city over the considered time period, and (ii) frame a number of scenarios reflecting the dynamic distribution of the different technologies of 
127 powertrain that meet the transport demand for the given time period. In the case study of Copenhagen, four

128 scenarios were investigated: two basis scenarios developed by McKinsey\& $\mathrm{Co}^{36}$, and two explorative 129 scenarios developed to investigate possibilities for significantly decreasing the environmental impacts of the 130 private passenger transport sector. McKinsey\& $\mathrm{Co}^{36}$ developed scenarios for the evolution of global market 131 shares of different powertrain technologies up to the year 2050 (see Supplementary Methods section 2.2).

132 Two scenarios were built based on hypothetical carbon emission averages for well-to-wheel emissions, 133 namely the "Below 100" scenario (B100) and the "Below 10" scenario (B10). B100 corresponds to a 134 business-as-usual scenario, in which the average private vehicle is associated with well-to-wheel emissions 135 below $100 \mathrm{~g}-\mathrm{CO}_{2} \mathrm{eq} / \mathrm{km}$ in 2050. In B100, EVs have limited deployment, and FCEVs do not enter the market 136 by 2030 . The B10 scenario corresponds to an emission target for average private vehicle of less than $10 \mathrm{~g}$ $\mathrm{CO}_{2} \mathrm{eq} / \mathrm{km}$ in 2050. In B10, REEVs and HEVs are transition technologies toward a large deployment of BEVs and FCEVs, deemed technically and environmentally more relevant.

We developed two explorative scenarios: the BEV++ and the FCEV++ scenarios. The BEV++ scenario is based on the B10 scenario, but includes faster technological changes: the proportion of BEVs thus increases and replaces HEVs sooner. The FCEV++ scenario models a potential disruptive technological advancement in FCEVs that accelerates their introductions from 2019 and on. In the FCEV++ scenario, REEVs act as the main transition technology as opposed to HEVs. See Supplementary Methods for more details.

The functional unit for the fleet-based LCA was defined here as the "supply of all the demand for private transportation via motorized passenger vehicles for the Copenhagen area from 2016 to 2030”. This FU can again be easily adapted to other cities and time frame. Each scenario is modeled as a dynamic system, which includes entire life cycles (i.e. raw materials extraction, production, use and decommissioning/disposal) of (i) the vehicles for all modeled technologies, (ii) the fuels (gasoline, diesel,

150 electricity and hydrogen supply systems), and (iii) all support systems, encompassing the electricity grid, the 151 roads and the EV-charging and fuel station infrastructures (see Figure 1). In the case of Copenhagen, 152 hydrogen stations were not included because of lack of data availability. The dynamic perspective is 153 provided by modeling the above systems with time differentiation. For the Copenhagen case, based on 154 available data, the characteristics of the vehicles were modeled following five-year intervals to simulate 
technological improvements, i.e. 2016-2020, 2020-2025 and 2025-2030, while the composition of the Danish electricity grid mix was changed every year.

\subsection{System modeling and data collection}

Data sources. Specific data pertaining to the modeling of the fleet system are to be collected from different sources and implemented into a LCA software, while the background data (e.g. for support systems) can rely on a life cycle inventory (LCI) database adapted to the country under study. In the present case study, we have used $\operatorname{SimaPro}^{37}$ (v.8.1.0.60) for the system modeling and have relied on the Ecoinvent database v.3.1 (consequential version), one of the largest life cycle inventory (LCI) databases ${ }^{38,39}$ for background data. A consequential modeling approach was adopted to include the consequences and interactions with other systems of the large-scale EV deployment at city level ${ }^{39}$, and thus system expansion was used for the multi-functionality of processes. Potential reinforcements of the electricity grid and further consequences of the positive public perception of electrified vehicles were not accounted for in the current study, but constitute interesting subjects for future research. Further details are available in SI Methods.

General data, such as population growth, proportion of people living in single houses and number of private cars per inhabitant were collected from official national statistics ${ }^{40}$. Parameters for the current Danish passenger vehicle fleet, e.g. average distances driven per day per car, were extracted from national surveys ${ }^{41}$. We assumed that vehicle ownership and other transportation habits, such as the average number of vehicles per inhabitant or average distances driven per day, remain constant over the period 2016-2030.

Vehicle technologies. The LCI for different vehicle powertrains are modeled, taking existing LCI processes in Ecoinvent v.3.1 $1^{38}$ and adapting several parameters, viz. vehicle weight, fuel consumption, lifetime of the vehicle and weight and lifetime of the battery (when applicable). The passenger cars modeled in the Ecoinvent database are equipped with gliders based on Volkswagen Golf $\mathrm{VI}^{42}$. They follow the EURO 5 standards for diesel and petrol cars and are equipped with Lithium-ion batteries for electric ones ${ }^{38,39}$. For each of the technologies, a base model can be developed for the beginning of the time-scope using the current average vehicle. For example, for Copenhagen, the ICV and BEV base models were built from the fleet-weighted average characteristics of corresponding vehicles in Denmark ${ }^{43,44}$. The HEV, REEV and FCEV base models were developed from the BEV base-model since these technologies are similar, yet rare or inexistent in the current Danish market. Vehicle characteristics such as battery specifications ${ }^{45}$, 
183

184

externalities and real-world fuel consumption ${ }^{42}$, fuel-cell inventories ${ }^{46}$, utility factors ${ }^{47}$ and specificities regarding $\mathrm{ICVs}^{48}$ were collected from scientific literature and governmental reports. These specific data needs are illustrated in Figure 1, and are fully documented in SI Methods.

At each time step defined by the dynamic perspective, a new average vehicle model specific to each technology is introduced, thus creating evolving models over the assessed time period (see Figure 1). The characteristics of the new vehicle models vary from the base-models: vehicle weight, fuel consumption and battery weight (when applicable) are assumed to decrease over time, with selected reduction rates. The vehicle and battery lifetimes are assumed to stay constant over the time scope and are thus modeled similarly to the LCI processes used in Ecoinvent v.3.1, i.e. $150,000 \mathrm{~km}$ for vehicles and 100,000 km for batteries. ${ }^{39}$ For Copenhagen, based on data availability, a time step of five years was selected, so three models in total were developed for each of the five technologies (i.e. for 2016-2020, 2021-2025 and 2026-2030), with reduction rates of $1.2 \% /$ year for the vehicle weight, $2.5 \% /$ year for the fuel consumption and $1.25 \% /$ year for the electricity consumption ${ }^{23,49}$. An exception lies in the FCEVs, which only had one model for the 15 years because of their current lack of maturity. At the end of life, the vehicles are entirely recycled as defined by default for passenger cars in the consequential database of Ecoinvent ${ }^{42}$. Due to lack of data, the evolution of materials for car manufacturing over time was disregarded although these materials are likely to evolve through the years to become lighter and have different lifetimes and properties ${ }^{50}$. Future studies may explore how to consistently include these prospective aspects in the vehicle system modeling.

Charging infrastructures. Some EVs (e.g. BEVs or PHEVs) require specific charging infrastructures, which are in general not available yet in cities at large scale. If an increasing deployment of these technologies is made, more and more charging infrastructures will be installed within the considered time frame, which is taken into account in the framework. In the case study, the chargers were separated in three types: home chargers, fast public chargers and normal public chargers ${ }^{51}$. We made the assumption that owners of EVs living in private housing will install a home charger. Fast public chargers are not essential, but substantially increase the convenience of owning a BEVs since it allows the owner to drive a bigger distance than the driving range in its travels; their implementation therefore depends on the willingness of the city. With regard to normal public chargers, different methods have been used in previous studies to estimate their requirements for EV deployment ${ }^{51-55}$. Primarily, local scenario that have been developed for 
211 the zone under study by transportation specialists or urban developers should be investigated. If such an

212 assessment does not exist, they can use the general methodology developed in this paper and described in SI

213 Method (section 2.4.2. Method 3). For Copenhagen, a methodology specifically developed for the situation

214 of Denmark in the case of an increasing deployment of BEVs in the whole country was selected: it defined

215 the number of chargers required per city based on the actual urban density of each zone for a comfortable use

216 of EVs. $^{54}$

217 Fuel and electricity systems. The study being consequential, marginal production technologies were

218 required for the different energy processes ${ }^{56}$. A mix of long-term marginal technologies is typically

219 recommended along with explorative scenarios ${ }^{57,58}$. Because our time scope begins in 2016 and only goes

220 until 2030, the electricity mix used in this article could better be qualified as a "medium-term" marginal mix.

221 We recognize that the medium-term marginal mix of fuels may change over the considered time scope.

222 Including this evolution by anticipating it based on national and international targets and forecasting scenarios increase the representativeness of the model. In the case of Denmark from 2016 to 2030, the evolution of the medium-term marginal electricity production mix was modeled by taking the Ecoinvent process and adapting it by extrapolating the goals that the Danish government and the European Union have established for 2020 and $2030^{59-61}$. Denmark has established a target have a fossils-free electricity mix by $2035^{59}$. The electricity grid mix was thus modeled to evolve from a currently coal-driven production to a wind-driven production in 2030 , with approximately $15 \%$ of fossil fuels. Owing to the use of a medium-term marginal mix and with no guarantee that the deployment of EVs will be accompanied with an increase in electricity demand over 2016-2030 (due to other potentially-compensatory factors such as energy efficiency gains, change in transportation patterns like car sharing, storage from renewable sources, etc.), we have retained a share of coal in the medium-term mix. The modeling of the electricity medium-term marginal is an important source of uncertainties, which has been assessed through a sensitivity analysis. Background processes, e.g. fossil fuels and hydrogen supply, were modeled using the default marginal processes from the

235 Ecoinvent database. Albeit deemed of little influence on the results of this study, inconsistencies associated with the lack to temporal variations in the background processes should be investigated in future studies. 


\subsection{Life cycle impact assessment}

Life cycle impact assessment (LCIA) is an LCA methodological phase translating pollutant emissions and resource consumptions into potential impacts on ecosystems, human health, and natural resources. In the current study, it was performed using ILCD 2011 methodology at midpoint level (v.1.07), which has been recommended as best LCIA practice for Europe by the EU Commission ${ }^{12,62}$.

Fifteen impact categories were considered, including climate change, stratospheric ozone depletion, toxic impacts on human health from released chemicals (termed as "human toxicity" in the following; differentiated between cancer effects and non-cancer effects), toxic impacts on freshwater ecosystems from released chemicals (termed as "ecotoxicity" in the following), particulate matter formation, ionizing radiation impact on human health, acidification, photochemical ozone formation, eutrophication (differentiated between impacts on freshwater, marine and terrestrial ecosystems), land use, water resource depletion and mineral, fossil and renewable resource depletion ${ }^{62}$.

\section{Application of the framework to the vehicle-based LCA}

The vehicle-based LCA is based on the functional unit of different vehicles driving of $1 \mathrm{~km}$ in 2016 or in 2030 as a comparison basis (see Section 2.2). Results for the environmental performances of the five powertrain technologies in 2016 and 2030 are fully documented in the SI (Tables S1 and S2).

\subsection{Overall trends}

In 2016, the ranking of the different technologies is strongly dependent on the impact category, with ICV performing worst for 5 impact categories while performing best for 6 impact categories (out of the 15 midpoint impact indicators) - see Figure S1. BEVs and REEVs have the lowest impact results in 5 and 4 other impact categories, respectively. This shows that, considering current technologies in 2016, several environmental trade-offs can be observed between the different technologies.

In 2030, FCEVs have the lowest environmental impacts in 9 categories, and the worst in only one (stratospheric ozone depletion), even though that technology is still immature (see Section 2.4). These high impacts in stratospheric ozone depletion stem from the fuel cells production, and more precisely to the tetrafluoroethylene production, which is associated with important emissions of required trichloromethane. 
FCEVs thus have potential to reduce environmental impacts of the transport sector by 2030 . However, this

affirmation must be regarded with caution because of the lack of maturity of that technology and thus the limited information currently available to describe it compared to the other powertrains. With regard to the other technologies, impacts generally decrease from 2016 to 2030 regardless of the impact category.

\subsection{Influence of electricity requirements for EVs and grid mix composition}

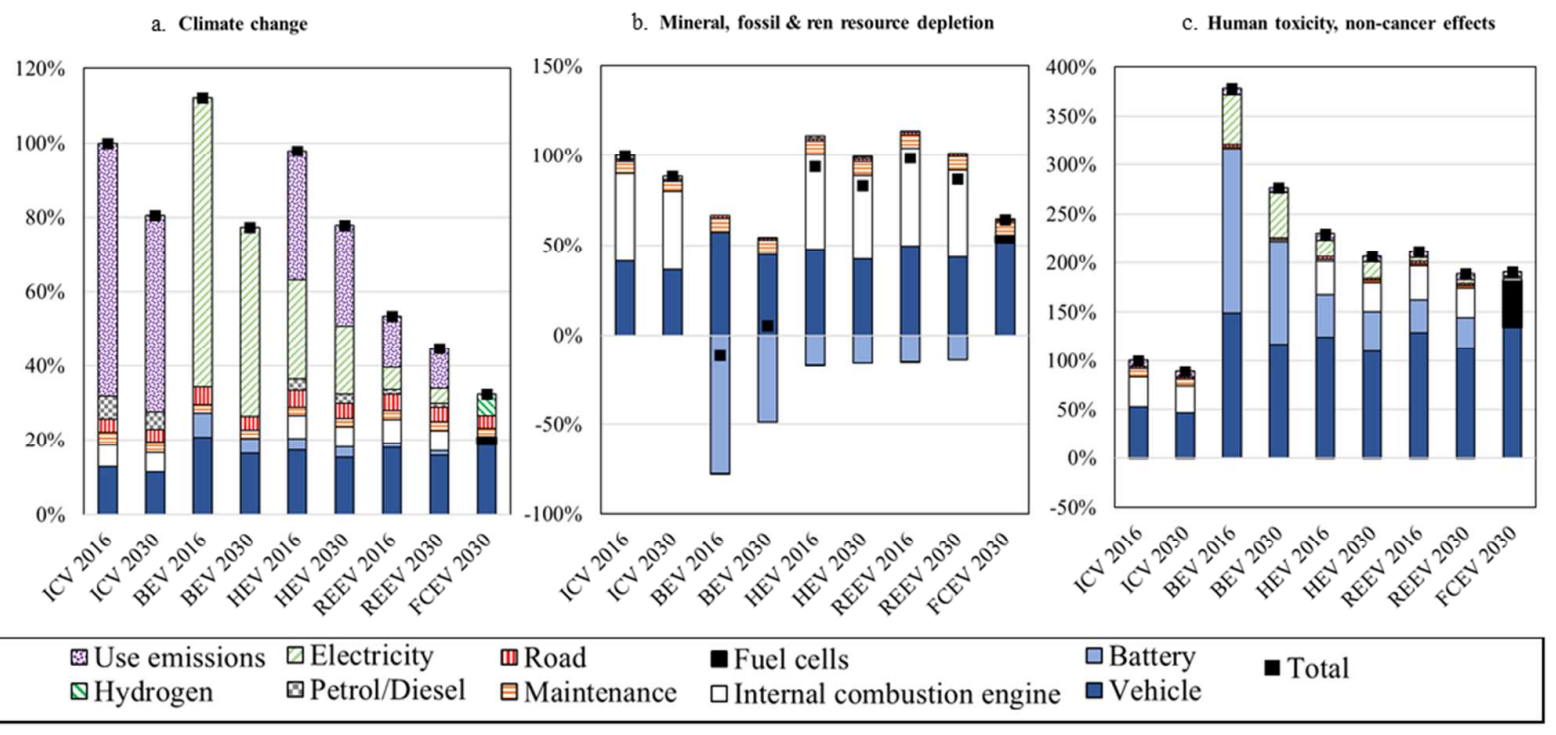

Figure 2: Comparison of the five technologies of vehicle in 2016 and 2030 based on the driving of $1 \mathrm{~km}$ in a passenger car for the selected impact categories climate change (a), mineral, fossil \& renewable resource depletion (b), and human toxicity (non-cancer effects) (c). Results are differentiated by process contribution and indexed on the impact scores obtained for internal combustion engine vehicles in 2016 (set to 100\%). Results for the remaining impact categories are available in Figures S2-S16.

ICVs are generally regarded as large GHG emitters and hence important contributors to climate change ${ }^{5}$. Because of potentially highly-impacting electricity grid mixes (e.g. grid mixes with high share of coal), alternative technologies may also be associated with large impacts on climate change. For Copenhagen, as illustrated in Figure 2a, the climate change impacts for BEVs are thus found slightly higher than that for ICVs in 2016 (i.e. 292 and 261 g-CO2eq/km respectively) and slightly lower in 2030 (i.e. 202 and $210 \mathrm{~g}-\mathrm{CO} 2 \mathrm{eq} / \mathrm{km}$ respectively). This finding is in contrast with most studies that have compared ICVs and BEVs. As illustrated in Figure 3, previous studies ${ }^{19,63,64}$ found that climate change impacts of BEVs decreased from $21 \%$ to $41 \%$ and estimated that by 2030 it could be reduced by up to $65 \%{ }^{19}$. 

electricity requirements of EVs. Huo et al. ${ }^{65}$ reported that the climate change impacts per kilometer varied by up to $200 \%$ depending on the electricity mix. In Denmark, in 2016, approximately $55 \%$ of the marginal electricity was generated from coal, thus partly explaining the observed differences with previous studies, which looked at more renewable mixes.

In addition, the relative poor environmental performance of BEV may be explained by the nature of the EV fleet in Copenhagen, which is currently largely composed of high standing vehicles that are considerably more powerful and heavier than the average ICV and thus intrinsically consume more fuel. This extra fuel demand is further increased because of the weather conditions in Denmark. Unlike ICVs, which can divert some of the heat loss from the combustion to the heating of the vehicles, EVs require additional electricity demand when heating is required. Denmark having a relatively cold climate, a larger amount of electricity is therefore used for heating the vehicle than it is in southern countries, on which previous studies have focused (e.g. Spain ${ }^{42}$ ). These findings demonstrate the importance that the electricity grid composition

On the other hand, ICVs have impacts on human health that are not taken into account with this LCIA method. The largest climate change impacts for ICVs stem from exhaust emissions, whereas for BEVs, electricity production is the main driver. Thus, ICVs contribute to air pollution while the vehicle is used, predominantly within cities. In contrast, electricity production is typically located away from urbanized areas, and thus has less impact on human health, leading to a geographical burden-shifting of impacts. The LCIA method used here do not take these geographical differences into account. Therefore, the health impact of ICVs might be underestimated (or the health impact of BEVs overestimated).

\subsection{Other EV powertrain technologies than BEV}

Comparing our results to previous studies is challenging because of the few studies retrieved on other powertrains than ICVs and BEVs, particularly REEVs and FCEVs. Additionally, their results vary considerably depending on, e.g., hydrogen production means. ${ }^{66-68}$ In general, previously-reported impacts scores are higher than those in the current study (see Figure 3). Bauer et al. ${ }^{19}$ studied a FCEV in the year 2030 and compared different hydrogen production paths, and reported climate change impacts varying from 
313 the same to approximately 3 times higher than those in the present study. Hydrogen production thus

314 contributes in average to $75 \%$ of the total impacts in Bauer et al. ${ }^{19}$, while in the current study, which

315

316 considers the Ecoinvent process that mainly relies on natural gas reforming for producing hydrogen ${ }^{69}$, it corresponds to less than $25 \%$.

However, it should be noted that the current study was conducted using a consequential modeling framework, whereas most of the previous studies considered in Figure 3 used an attributional modeling framework (excluding Tagliaferri et al. ${ }^{70}$ ). The attributional approach focuses on accounting for the used resources and emissions that can be assigned to a system life cycle taken in isolation, while the consequential approach also addresses the consequences that the system implementation may cause to the rest of the economy, i.e. other systems ${ }^{13,71}$. Therefore, the results displayed in Figure 3 should be regarded with caution, as some discrepancies may be explained by modeling differences, e.g. modeling of multi-functional processes.

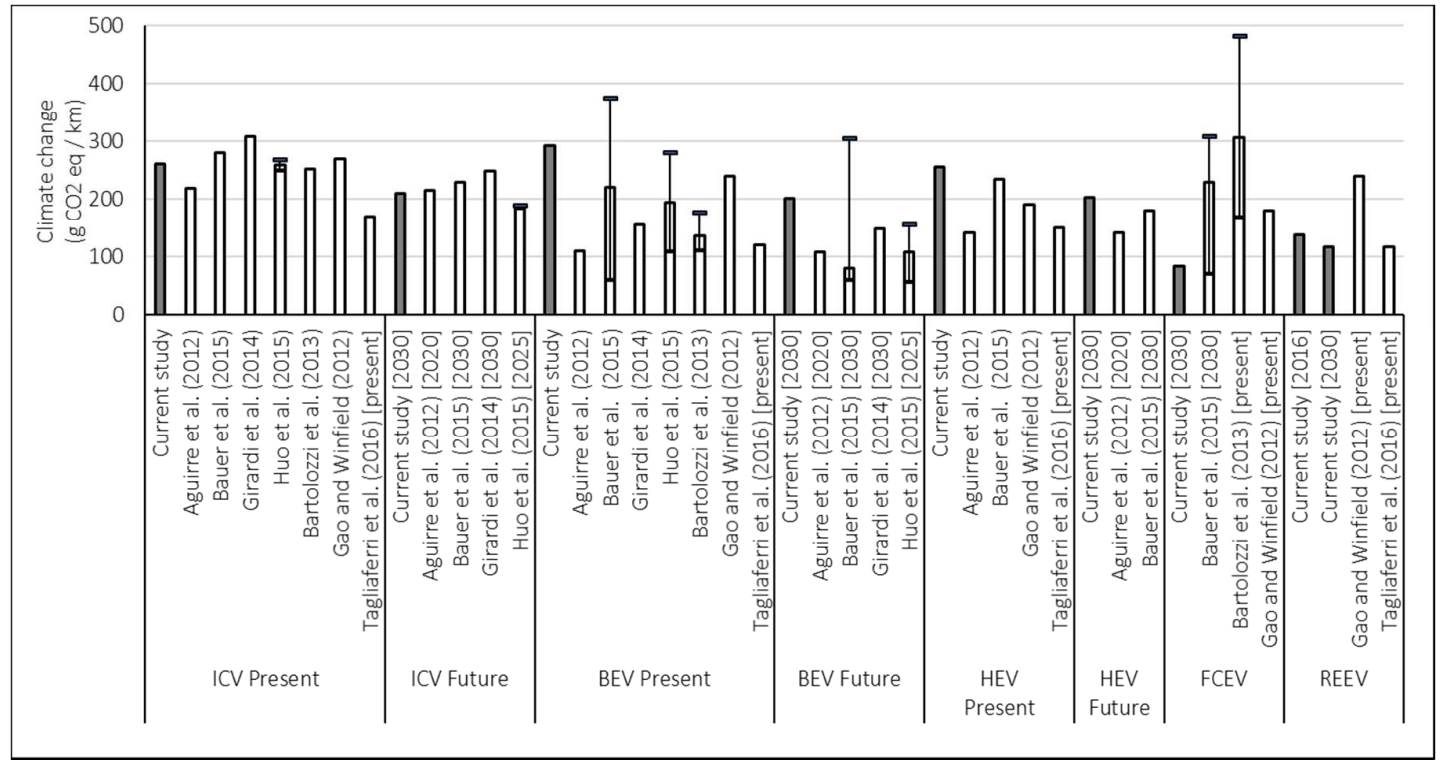

Figure 3: Characterized results for climate change for the different technologies of vehicles found in the current study (grey bars) and in other literature sources (white bars). Huo et al. (2015) ${ }^{65}$, Bauer et al. $(2015)^{19}$ and Bartolozzi et al. (2013) ${ }^{66}$ studied different scenarios of electricity, fuel and hydrogen production: therefore the bars represent the mean scores while the whiskers indicate the minimum and maximum scores obtained.

\subsection{Contribution of the vehicle life cycle stages}

The same distribution of impacts between life cycle stages is observed between 2016 and 2030 (see Figures S17-S25). Manufacturing and use of the vehicles are the two main contributors to environmental 
334

335

336

337

338

339

340

341

342

impacts with important variations in the total contributions across impact categories. Contributions up to $90 \%$ of the final score are found for some impact categories, e.g. acidification potential for ICVs and climate change for BEVs. The impacts of the vehicle manufacturing stage mainly stem from steel and copper mining activities for human toxicity, freshwater eutrophication, water depletion and resource depletion as well as from the use of palladium in the catalytic converters of vehicles having an internal combustion engine for particulate matter and acidification impact categories. Important contributions of the end-of-life of ICVs to the total environmental burden are observed for acidification and freshwater ecotoxicity due to the dismantling of the internal combustion engine, which is associated with emissions of heavy metals (from processing of metal parts) and ammonia/NOx (from use of solvents).

Figure 2 and Figures S2-S16 highlight the risk of burden-shifting that may occur when a switch across different powertrain technologies occurs in the future, with the source of the impacts primarily located in either the use stage or the manufacturing stage, depending on the impact category. For example, while the production of fuels and the use stage (incl. electricity generation for EVs) are responsible for more than 60$70 \%$ of the climate change scores for ICV, HEV and BEV, human toxicity impacts and resource depletion are dominated by the manufacturing processes that account for more than $90 \%$ for these three technologies (Figure $2 \mathrm{a}, 2 \mathrm{~b}$ and $2 \mathrm{c}$ ). For all types of vehicles, the processes contributing the most to human toxicity impacts are the sulfidic tailings for non-cancer effects and the landfilling of steel from the glider for cancer effects. However, to reduce most impacts of the new EV technologies, the environmental performances of the electricity grid mixes and the electricity efficiency for the operation of the car are the most important when addressing BEVs, while car manufacturing is the most important impact stage with respect to FCEV and REEV.

In contrast with the results for climate change, BEVs are found to have the lowest resource depletion impacts due to the battery, i.e. $-5.09 \mathrm{mg}-\mathrm{Sb}-\mathrm{eq} / \mathrm{km}$ in 2016 and $2.38 \mathrm{mg}-\mathrm{Sb}-\mathrm{eq} / \mathrm{km}$ in 2030 (cf. Figure 2b). The study being consequential, negative scores are explained by avoided burdens associated with avoided production of virgin materials. The avoided production of pure cobalt due to recycling is found to account for $97 \%$ of the battery positive contribution to resource depletion for BEVs in 2016 . However, the feasibility of such an efficient disposal plan is debatable because an increasing demand for BEVs will increase the demand of lithium and cobalt drastically and in a shorter time than the battery lifetime, thus exceeding the 
362

363

364

365

366

367

368

369

370

371

372

373

374

375

376

377

378

379

380

381

382

383

384

385

386

387

capacity of available recycled materials. Such a perspective was not included in the current study although it should be investigated in future works. Likewise, the acidification results of the partially to totally electrified vehicles are much lower than the ones from ICVs because of the negative impact scores from the vehicle part. For the EVs it stems from the recycling of the electronic scraps and the resulting recovery of valuable metals like rhodium, thus saving acidic processing of virgin materials (see Figure S9), while the ICVs' acidification score is primarily caused by the mining of the Palladium for the combustion engine.

\section{Application of framework to fleet-based LCA}

Building on the comparisons of the vehicle system, the application of the framework to assess the environmental performances of fleet-based scenarios is illustrated below with the case of Copenhagen and its four considered EV deployment scenarios (see Section 2.3).

\subsection{Analysis of the cumulative impacts over the 15 years}

The assessment enables to compute cumulative impacts over the considered time period, which can provide insights into potential long-term benefits. For Copenhagen, Table S3 and S4 show the differences and the ranking of the scenarios for the 15 categories assessed over the 15 years. No scenario appears better than the others for all impact categories, and the ranking of the four scenarios therefore varies depending on the impact category considered. Benchmarking against the business as usual scenario for Copenhagen, i.e. B100, the largest environmental gains are obtained for FCEV++, which decrease acidification impacts by $71 \%$ and all the other impacts by $2-39 \%$, except for toxic impacts (increase by $7-43 \%$ ), water resource depletion $(+38 \%)$ and freshwater eutrophication $(+58 \%)$.

These results are however associated with uncertainties as the modeling of FCEVs does not include the hydrogen supply infrastructure, i.e. the transport and the distribution of $\mathrm{H} 2$. The overall contribution of such infrastructure to the total environmental impacts was found to be negligible for other powertrain technologies (see Figure S26), hence this assumption is believed to be acceptable. As another source of uncertainties, the data used to model the FCEV in the period 2026-2030 rely on lab-scale or small pilot/commercial scale data, which do not have the same level of maturity as the other analyzed technologies. 
388

389

390

391

392

393

394

Increases in the manufacturing and disposal process efficiencies when developing FCEV technologies at full commercial scale may therefore be expected, thus leading to lower impacts ${ }^{72}$. The observed results combined with such prospects therefore suggest that FCEVs are an environmentally-promising EV technology and may indicate overall better performances of the FCEV++ scenario over other assessed scenarios. Further conduct of similar LCA studies to other cities with different settings are needed to assess whether this tendency is generic or only applicable to specific situations due to influence of local parameters, e.g. grid mixes, transport needs, etc.

\subsection{Annual evolution of the impacts}

In addition to a cumulative assessment, the fleet-based results can also enable to show annual evolution of the impacts. Figure 4 illustrates the annual evolution of the four modeled scenarios in the 15 impact categories for Copenhagen. It demonstrates that the ranking of the four scenarios is not only dependent on the impact categories (see Section 4.1) but also changes over time (curves crossing each other in Figure 4). These changes have the same trends for BEV++ and B10, always having the same ranking with B100, whereas FCEV++ presents different tendencies because of the bigger difference of powertrain distribution over the years (Figure S27). For instance, when looking at photochemical ozone formation, $\mathrm{BEV}++$ and $\mathrm{B} 10$ have higher impacts than B100 over the whole period considered, while FCEV++ presents lower scores from 2024.

In the year 2030, FCEV++ only have higher impact scores in two categories (ozone depletion and water resource depletion), whereas it has the lowest score for 9 categories, including climate change. Some impact categories are observed to increase over time, such as human toxicity and freshwater eutrophication, while others decrease, e.g. climate change and acidification (see Figure 4). This demonstrates that environmental burden-shifting may be expected through the deployment of EVs in Copenhagen in the period 2016-2030, to which stakeholders should pay attention. From Figure 4, human toxicity (up to $150 \%$ increase in 2030 compared to 2016$)$, water depletion (100\% increase), freshwater ecotoxicity ( $50 \%$ increase) and eutrophication (200\% increase) are the impact categories, which stakeholders thus need to tackle along with their development and implementation of the EV technologies.

A founding hypothesis of these scenarios is that the current city transportation model (e.g. driver's habits, average distance driven per inhabitant per day, preference regarding the mean of transportation, etc.) 
will not change until 2030. However, new tendencies regarding mobility such as car sharing or ride-hailing applications are emerging and might change the city mobility as we know it today. This could change the results found in this study and present a more environmental friendly solution, as it may tend to reduce the use of individual vehicles.
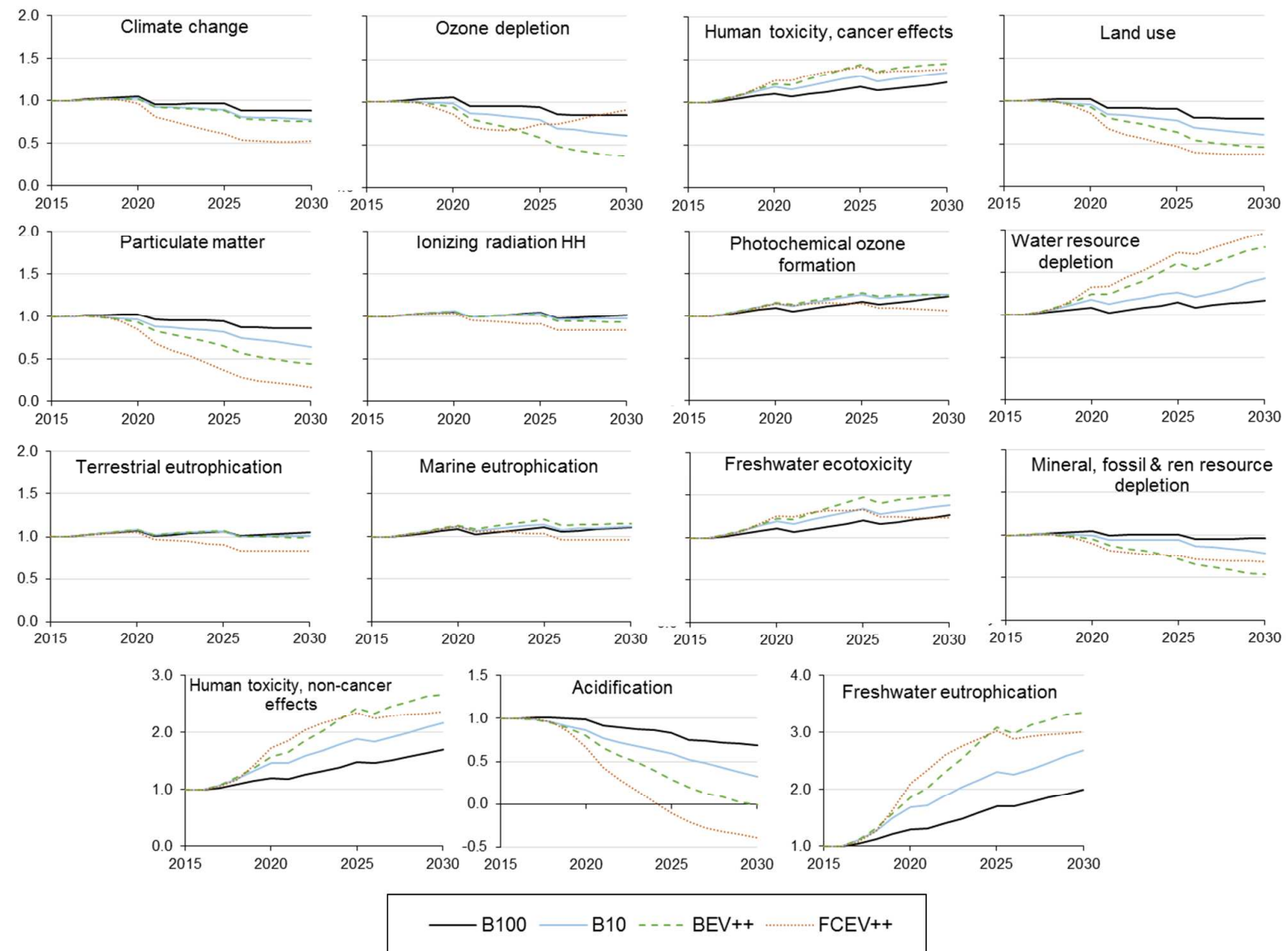

Figure 4: Evolution of the annual environmental impact scores for the four considered scenarios B10, B100, $\mathrm{BEV}++$ and FCEV++ for the 15 impact categories (results indexed on the impact scores in 2016, which are the same in all scenarios). Slight breaks in the curves in 2020 and 2025 are caused by discontinuous changes in the technologies' characteristics (see section 2.4). Note that the scale is the same for all the categories but human toxicity (non-cancer effects), acidification and freshwater eutrophication (lowest row of graphs).

\subsection{Importance of infrastructures and vehicles types}

At the fleet level, infrastructures were found to have an overall negligible impact, with contributions below $3 \%$ of the scenario total scores over the 15 years, regardless of the impact category and scenario (Figures S26 and S27). This score cannot be directly compared to previous literature because it refers to the whole fleet. However, Lucas et al. ${ }^{73}$ reported an impact of charging infrastructures of $8-12 \%$ of the energy demand and climate change impacts per kilometer driven by BEVs, which is in line with what is found in 
433

434

this study when the scope is adapted. These findings indicate that although the impacts of infrastructure is noticeable on a per-kilometer basis, it is negligible when considering the entire system compared to the impacts from vehicles.

With regard to vehicle types, scenarios B10, BEV++ and B100 show similar trends for nearly all impacts, with major contributions from the vehicle manufacturing and the vehicle use stage (fuel combustion or electricity production). The relative balancing between the two is strongly impact-specific (Figure S26). In contrast, in the FCEV++ scenario, the vehicle manufacture becomes a more important driver of impacts, with contributions higher than those in B10 and B100 for 10 out of 15 impact categories. For example, for human toxicity (non-cancer), the contribution of the vehicle manufacturing stage in FCEV++ is almost twice the contribution in B100. This trend in FCEV++ is largely influenced by the dominant proportion of FCEVs in the fleet (ca. 50\%). Considering these results, the implementation of such a scenario should therefore be accompanied with a strong focus to reduce the environmental impacts from the manufacture of FCEVs, which is the primary cause for the burden-shifting observed in Figure 4 (e.g. fuel cell production; see Section 4.2).

The importance of electricity production varies across impact categories. The electricity grid mix is a key driver of impacts for climate change and eutrophication impact categories, whereas it has a minor impact for the remaining impact categories (see Section 3.2). The electricity production impacts associated with BEVs and HEVs largely decrease between 2016 and 2030 for all impact categories except resource depletion (see Figure 2 and S2-S16). This is mainly explained by a "cleaner" electricity generation, which switches from 50\%:33\% of coal:wind in 2016 to $16 \%: 55 \%$ in 2030, thus reducing the overall environmental impact. The scarce resources used in the construction of wind turbines result in an increase of the resource depletion impacts between 2016 and 2030, but the share of electricity production in BEVs' resource depletion impacts is so low that it has no influence (Figure 2b). Therefore, the use of EVs may bring particularly large environmental benefits in countries that have low carbon electricity mixes such as Norway, which is producing over $95 \%$ of its electricity via hydropower ${ }^{74}$. It is however worth noting that the effects of the introduction of EVs on the electricity mix are not assessed in details in this study and they might alter the composition and efficiency of the electricity grid, thus resulting in possibly different environmental impact profiles. Investigation of the influence of such feedback mechanisms is an area for future research. 


\subsection{Robustness of the assessment relatively to its inputs}

462

To ensure reliability in the support provided to stakeholders, the robustness of their assessments

463

464

465

466

467

468

469

470

471

472

473

474

475

476

477

478

479

480

should be tested by performing uncertainty and sensitivity analyses. ${ }^{12,13}$ The two largest uncertainty sources can be expected to stem from the modeling of the dynamic perspective that can be divided in two types: (1) the system modeling, i.e. how the temporal dimensions are addressed by making parameters vary or assumed fixed; and (2) the input data for the model, also requiring temporal variation.

In the current study, a sensitivity analysis on several input parameters was thus conducted to evaluate the robustness or stability of the environmental impacts of the systems. The tested parameters included (i) the average size of BEVs, (ii) the fuel consumption reduction rate for ICVs, BEVs, HEVs and REEVs, and (iii) the composition of the electricity mix. As documented in Tables S5-S7 and Figures S28S30, none of these parameters led to a significant influence on the results, thus suggesting a high level of robustness in the findings of the study. For example, after changing the proportion of large BEVs to only $10 \%$, the results changed by less than $2 \%$.

To test the validity of the assumptions regarding the charging infrastructures, different modeling approaches were additionally tested (see details in SI Methods). The results showed that even when the total number of required charging stations increases by up to $200 \%$, the contribution of the infrastructures to the impacts remains below $5 \%$. Thus, the choice of the infrastructure method has very little influence on the results although it should be noted that the different types of charging infrastructures are not assumed to change from 2016 to 2030. New ways of charging cars may be found and implemented, thus altering the contribution of infrastructure to the total environmental impact.

\section{Recommendations and outlook for urban transport assessment}

The LCA framework demonstrated in this study enables consistent and comprehensive vehicle-based and fleet-based LCA. The framework highlights the importance for including in the assessment multiple types of powertrains as a reflection of future potential markets, and not just limiting its scope to ICVs and BEVs. 
Several methodological learnings can be highlighted. With respect to the fleet perspective, the case study of Copenhagen revealed the need for including in the assessment multiple types of powertrains as a reflection of future potential markets, and not just limiting its scope to ICVs and BEVs as several previous studies have done. In addition, it demonstrates the necessity of considering all relevant environmental impact categories in order to identify potential environmental burden-shifting. To move these conclusions to a foresight perspective, the inclusion of technological improvements in the construction of the assessment model and the change in the main characteristics of the vehicles and support systems (e.g. electric grid mix) over time should be considered. We therefore believe that our framework and methodological approach can be reproduced to other case studies and cities, while fine-tuning some of its components. In future LCA studies, we recommend LCA practitioners to rely on the learnings from the proof-of-concept of Copenhagen, where data needs and hotspots have been highlighted.

The results of our LCA study on Copenhagen also enabled us to identify key recommendations to transport system stakeholders. With our current modeling, BEVs were not found to be effective in reducing environmental impacts in Denmark. Denmark's cold climate requires significant heating of the vehicle interior, which, for ICVs, is provided by the heat loss of the internal combustion engines but implies extra energy consumption in the case of EVs because of the lower heat generation of the electric motor. The current luxury status of BEVs in Denmark also leads to the modeling of large, heavy vehicles which are associated with higher electricity consumption than average size vehicles. In addition, the Danish electricity grid consumes a large share of coal, thus leading to relatively high environmental impacts in the use stage compared to ICVs. The use of BEVs in other locations, e.g. southern countries, with electricity generation that utilizes high shares of renewables, is likely to reduce significantly these environmental impacts, and thus render BEV a more attractive technology.

In all scenarios, charging infrastructures were found to have a negligible impact on the results, which suggest that urban transport planning should target more the vehicles and the supply of the fuel or electricity most attractive of the scenarios. Because of the current immaturity of the fuel-cell technology, a transition technology to rapidly move away from fossil fuels is needed. In this context, REEVs seemed to act as an 
514 environmentally-promising technology. Both technologies, which have been largely under-investigated in 515 past LCA studies, should therefore be further assessed in future studies, accounting for the aforementioned 516 recommendations. In a wider perspective, the observation of environmental burden-shifting in all scenarios 517 also call for systematically associating the conduct of full life cycle assessment to transport planning to avoid 518 that relevant environmental impact increase while targeted impacts are being decreased.

Supporting Information. Contains Supplementary Figures S1-S30 (comparison of the final scores of the

521 vehicles in 2016 and 2030, component contribution in the 15 impact categories, stage contribution for the 5

522 vehicles in 2016 and 2030, stage contribution in the scenarios, powertrain contribution in the scenarios,

523 sensitivity analysis), Supplementary Tables S1-S7 (characterized results for the vehicles and the scenarios, 524 differences between scenarios and sensitivity analysis) and Supplementary Methods (calculations details of the construction of the model, including characteristics of the vehicles and definition of the scenarios).

Acknowledgements. The authors thank Jesper Henry Skjold and Jeppe Wraae Nielsen for the data they have provided for the Copenhagen case study and the discussion about the current and future electrification of the Danish private fleet, as well as Michael Zwicky Hauschild for the discussion and his useful insights regarding system modeling. 


\section{REFERENCES}

(1) Bilgin, B.; Magne, P.; Malysz, P.; Yang, Y.; Pantelic, V.; Preindl, M.; Korobkine, A.; Jiang, W.; Lawford, M.; Emadi, A. Making the Case for Electrified Transportation. IEEE Trans. Transp. Electrif. 2015, 1 (1), 4-17.

(2) Holtsmark, B.; Skonhoft, A. The Norwegian support and subsidy policy of electric cars. Should it be adopted by other countries? Environ. Sci. Policy 2014, 42, 160-168.

(3) Steen, M. Van Der; Schelven, R. M. Van; Kotter, R. E-Mobility in Europe. 2015.

(4) EAFO. Electric vehicle charging infrastructure http://www.eafo.eu/electric-vehicle-charginginfrastructure.

(5) IPCC. Climate Change 2014: Synthesis Report. Contribution of Working Groups I, II and III to the Fifth Assessment Report of the Intergovernmental Panel on Climate Change; Core Writing Team, Pachauri, R. K., Meyer, L. A., Eds.; Intergovernmental Panel on Climate Change: Geneva, Switzerland, 2014.

(6) Fenger, J. Air pollution in the last 50 years - From local to global. Atmos. Environ. 2009, 43 (1), 1322.

(7) IEA. Transport, energy and co2 - Moving Toward Sustainability; International Energy Agency: Paris, FR, 2009.

(8) Capellán-Pérez, I.; Mediavilla, M.; de Castro, C.; Carpintero, Ó.; Miguel, L. J. Fossil fuel depletion and socio-economic scenarios: An integrated approach. Energy 2014, 77, 641-666.

(9) Sadek, N. Urban electric vehicles: A contemporary business case. Eur. Transp. Res. Rev. 2012, 4, 27 37.

(10) Lave, L. B.; Hendrickson, C. T.; McMichael, F. C. Environmental implications of electric cars. Science. 1995, 268 (5213), 993-995.

(11) Hauschild, M. Z. Assessing Environmental Impacts in a Life-Cycle Perspective. Environ. Sci. Technol. 2005, 39 (4), 81-88.

(12) EC. International Reference Life Cycle Data System (ILCD) Handbook: Recommendations for Life 
Cycle Impact Assessment in the European context, First Edit.; Publications Office of the European Union: Luxembourg, 2011.

559

(13) EC. International Reference Life Cycle Data System (ILCD) Handbook: General guide for Life Cycle Assessment - Detailed guidance, First Edit.; Publications Office of the European Union: Luxembourg, 2010.

(14) ISO. ISO 14044:2006 - Environmental management - Life cycle assessment - Requirements and guidelines; Geneva, Switzerland, 2006.

(15) ISO. ISO 14040:2006 - Environmental management - Life cycle assessment - Principles and framework; Geneva, Switzerland, 2006.

(16) Hawkins, T. R.; Gausen, O. M.; Strømman, A. H. Environmental impacts of hybrid and electric vehicles-a review. Int. J. Life Cycle Assess. 2012, 17 (8), 997-1014.

(17) Nordelöf, A.; Messagie, M.; Tillman, A. M.; Ljunggren Söderman, M.; Van Mierlo, J. Environmental impacts of hybrid, plug-in hybrid, and battery electric vehicles - what can we learn from life cycle assessment? Int. J. Life Cycle Assess. 2014, 19 (11), 1866-1890.

(18) Miotti, M.; Hofer, J.; Bauer, C. Integrated environmental and economic assessment of current and future fuel cell vehicles. Int. J. Life Cycle Assess. 2015, 22, 1-17.

(19) Bauer, C.; Hofer, J.; Althaus, H.-J.; Del Duce, A.; Simons, A. The environmental performance of current and future passenger vehicles: Life cycle assessment based on a novel scenario analysis framework. Appl. Energy 2015, 157, 871-883.

(20) Laurent, A.; Espinosa, N. Environmental impacts of electricity generation at global, regional and national scales in 1980-2011: what can we learn for future energy planning? Energy Environ. Sci. 2015, $8(3), 689-701$.

(21) European Comission. Better Regulation Guidelines. Commission staff working document. COM (2015) 215 final; SWD(2015) 111 final.; EU Commission: Strasbourg, FR, 2015.

(22) Field, F.; Kirchain, R.; Clark, J. Life-cycle assessment and temporal distributions of emissions: Developing a fleet-based analysis. J. Ind. Ecol. 2000, 4 (2), 71-91. 
583

584

585

586

(23) Garcia, R.; Gregory, J.; Freire, F. Dynamic fleet-based life-cycle greenhouse gas assessment of the introduction of electric vehicles in the Portuguese light-duty fleet. Int. J. Life Cycle Assess. 2015, 20 (9), 1287-1299.

(24) Bandivadekar, A. E. A. On the Road in 2035 - Reducing transportation's petroleum consumption and GHG emissions; 2008.

(25) Garcia, R.; Freire, F. Marginal Life-Cycle Greenhouse Gas Emissions of Electricity Generation in Portugal and Implications for Electric Vehicles. Resources 2016, 5 (4), 41.

(26) Zhao, Y.; Onat, N. C.; Kucukvar, M.; Tatari, O. Carbon and energy footprints of electric delivery trucks: A hybrid multi-regional input-output life cycle assessment. Transp. Res. Part D Transp. Environ. 2016, 47, 195-207.

(27) Miotti, M.; Supran, G. J.; Kim, E. J.; Trancik, J. E. Personal Vehicles Evaluated against Climate Change Mitigation Targets. Environ. Sci. Technol. 2016, 50 (20), 10795-10804.

(28) Onat, N. C.; Kucukvar, M.; Tatari, O.; Zheng, Q. P. Combined application of multi-criteria optimization and life-cycle sustainability assessment for optimal distribution of alternative passenger cars in U.S. J. Clean. Prod. 2016, 112, 291-307.

(29) Onat, N. C.; Noori, M.; Kucukvar, M.; Zhao, Y.; Tatari, O.; Chester, M. Exploring the suitability of electric vehicles in the United States. Energy 2017, 121, 631-642.

(30) Reiter, M. S.; Kockelman, K. M. Emissions and exposure costs of electric versus conventional vehicles: A case study for Texas. Int. J. Sustain. Transp. 2017, 11 (7), 486-492.

(31) Baptista, P. C.; Silva, C. M.; Farias, T. L.; Heywood, J. B. Energy and environmental impacts of alternative pathways for the Portuguese road transportation sector. Energy Policy 2012, 51, 802-815.

(32) Francois, C.; Gondran, N.; Nicolas, J. P.; Parsons, D. Environmental assessment of urban mobility: Combining life cycle assessment with land-use and transport interaction modelling - Application to Lyon (France). Ecol. Indic. 2017, 72, 597-604.

(33) Chester, M. V; Horvath, A. Environmental assessment of passenger transportation should include infrastructure and supply chains. Environ. Res. Lett. 2009, 4 (2), 24008. 
609

610

611

612

613

614

615

616

617

618

619

620

621

622

623

624

625

626

627

628

629

630

631

632

633

634

(34) City of Copenhagen. Copenhagen Climate Plan - The short version; City of Copenhagen: Copenhagen, DK, 2009.

(35) CNG Europe. Natural Gas Vehicles http://cngeurope.com/natural-gas-vehicles/ (accessed Aug 10, 2017).

(36) McKinsey \& Company. Boost! Transforming the powertrain value chain - a portfolio challenge; Berlin, DE, 2011.

(37) PRé Consultants. SimaPro 8.1; PRé: Amersfoort, Netherlands, 2016.

(38) Weidema, B. P.; Bauer, C.; Hischier, R.; Mutel, C.; Nemecek, T.; Reinhard, J.; Vadenbo, C. O.; Wernet, G. Data quality guideline for the ecoinvent database version 3; The ecoinvent Centre: St. Gallen, CH, 2013; Vol. 3.

(39) Wernet, G.; Bauer, C.; Steubing, B.; Reinhard, J.; Moreno-Ruiz, E.; Weidema, B. The ecoinvent database version 3 (part I): overview and methodology. Int. J. Life Cycle Assess. 2016, 21 (9), 1218 1230.

(40) Statistik Banken. Statistik Banken http://www.statistikbanken.dk/ (accessed Apr 14, 2016).

(41) The Danish National Travel Survey. The Danish National Travel Survey http://www.modelcenter.transport.dtu.dk/english/TU (accessed Apr 14, 2016).

(42) Del Duce, A.; Gauch, M.; Althaus, H. J. Electric passenger car transport and passenger car life cycle inventories in ecoinvent version 3. Int. J. Life Cycle Assess. 2016, 21 (9), 1314-1326.

(43) The International Council on Clean Transportation. European Vehicle Market Statistics Pocketbook 2015/16; International Council on Clean Transportation: Berlin, DE, 2015.

(44) Danske Bilimportører / Dansk Elbil Alliance. Personal communication. Copenhagen, DK, 2016.

(45) USABC. USABC Goals for Advanced Batteries for EVS - CY 2020 Commercialization; United States Advanced Battery Consortium, 2014.

(46) Simons, A.; Bauer, C. A life-cycle perspective on automotive fuel cells. Appl. Energy 2015, 157, 884-896.

(47) Domingues, A. R.; Marques, P.; Garcia, R.; Freire, F.; Dias, L. C. Applying multi-criteria decision 
635

636

637

638

639

640

641

642

643

644

645

646

647

648

649

650

651

652

653

654

655

656

657

658

659

660

analysis to the life-cycle assessment of vehicles. J. Clean. Prod. 2015, 107, 749-759.

(48) ACEA. Passenger Car Fleet by Fuel Type. Statistics provided by the European Automobile Manufacturers' Association http://www.acea.be/statistics/tag/category/passenger-car-fleet-by-fueltype (accessed Apr 14, 2016).

(49) Element Energy. Influences on the low carbon car market from 2020-2030 - Final report for Low Carbon Vehicle Partnership; Element Energy Limited: Cambridge, UK, 2011.

(50) Lewis, A. M.; Kelly, J. C.; Keoleian, G. A. Vehicle lightweighting vs. electrification: Life cycle energy and GHG emissions results for diverse powertrain vehicles. Appl. Energy 2014, 126, 13-20.

(51) Nègre, L. Livre Vert sur les infrastructures de recharge ouvertes au public pour les véhicules «décarbonés »; French government, Ed.; République Française: Paris, FR, 2011.

(52) Lucas, A.; Neto, R. C.; Silva, C. A. Energy supply infrastructure LCA model for electric and hydrogen transportation systems. Energy 2013, 56, 70-80.

(53) Lucas, A.; Silva, C. A.; Costa Neto, R. Life cycle analysis of energy supply infrastructure for conventional and electric vehicles. Energy Policy 2012, 41, 537-547.

(54) EDISON Consortium. Report Work Package 1.3 - Electric vehicles and the customers; EDISON Consortium: Kgs. Lyngby, DK, 2011.

(55) EPRI. Guidelines for Infrastructure Planning; Electric Power Research Institute: Palo Alto, CA, USA, 2014.

(56) Ekvall, T.; Weidema, B. P. System boundaries and input data in consequential life cycle inventory analysis. Int. J. Life Cycle Assess. 2004, 9 (3), 161-171.

(57) Schmidt, J. H.; Merciai, S.; Thrane, M.; Dalgaard, R. Inventory of country specific electricity in LCA - Consequential and attributional scenarios. Methodology report v2.; Aalborg, DK, 2011.

(58) Münster, M.; Meibom, P. Long-term affected energy production of waste to energy technologies identified by use of energy system analysis. Waste Manag. 2010, 30 (12), 2510-2519.

(59) The Danish Government. Energy Strategy 2050 - from coal, oil and gas to green energy; The Danish Ministry of Climate and Energy: Copenhagen, DK, 2011. 
661

662

663

664

665

666

667

668

669

670

671

672

673

674

675

676

677

678

679

680

681

682

683

684

685

686

(60) IEA. Energy Policies of IEA countries - Denmark 2011 Review; International Energy Agency: Paris, FR, 2011.

(61) IEA. Energy Policies of IEA countries - European Union 2014 Review; International Energy Agency: Paris, FR, 2014.

(62) Hauschild, M. Z.; Goedkoop, M.; Guinée, J.; Heijungs, R.; Huijbregts, M.; Jolliet, O.; Margni, M.; De Schryver, A.; Humbert, S.; Laurent, A.; et al. Identifying best existing practice for characterization modeling in life cycle impact assessment. Int. J. Life Cycle Assess. 2013, 18 (3), 683-697.

(63) Noshadravan, A.; Cheah, L.; Roth, R.; Freire, F.; Dias, L.; Gregory, J. Stochastic comparative assessment of life-cycle greenhouse gas emissions from conventional and electric vehicles. Int. J. Life Cycle Assess. 2015, 20 (6), 854-864.

(64) Onat, N. C.; Kucukvar, M.; Tatari, O. Conventional, hybrid, plug-in hybrid or electric vehicles? State-based comparative carbon and energy footprint analysis in the United States. Appl. Energy $\mathbf{2 0 1 5}, 150,36-49$.

(65) Huo, H.; Cai, H.; Zhang, Q.; Liu, F.; He, K. Life-cycle assessment of greenhouse gas and air emissions of electric vehicles: A comparison between China and the U.S. Atmos. Environ. 2015, 108, $107-116$.

(66) Bartolozzi, I.; Rizzi, F.; Frey, M. Comparison between hydrogen and electric vehicles by life cycle assessment: A case study in Tuscany, Italy. Appl. Energy 2013, 101, 103-111.

(67) Ashnani, M. H. M.; Miremadi, T.; Johari, A.; Danekar, A. Environmental Impact of Alternative Fuels and Vehicle Technologies: A Life Cycle Assessment Perspective. Procedia Environ. Sci. 2015, 30 (30), 205-210.

(68) Gao, L.; Winfield, Z. C. Life cycle assessment of environmental and economic impacts of advanced vehicles. Energies 2012, 5 (3), 605-620.

(69) Althaus, H.-J.; Chudacoff, M.; Hischier, R.; Jungbluth, N.; Osses, M.; Primas, A.; Hellweg, S. Life cycle inventories of chemicals; Dübendorf, 2007.

(70) Tagliaferri, C.; Evangelisti, S.; Acconcia, F.; Domenech, T.; Ekins, P.; Barletta, D.; Lettieri, P. Life 
687

688

689

690

691

692

693

694

695

696

697

698

699 cycle assessment of future electric and hybrid vehicles: A cradle-to-grave systems engineering approach. Chem. Eng. Res. Des. 2016, 112, 298-309.

(71) Bjørn, A.; Owsianiak, M.; Laurent, A.; Olsen, S. I.; Corona, A.; Hauschild, M. Z. Scope definition. In Life Cycle Assessment: Theory and Practice; Hauschild M.Z. et al., Ed.; Springer: Dordrecht, NL, 2018; pp 75-116.

(72) Hellweg, S.; Milà i Canals, L. Emerging approaches, challenges and opportunities in life cycle assessment. Science. 2014, 344 (6188), 1109-1113.

(73) Lucas, A.; Neto, R. C.; Silva, C. A. Impact of energy supply infrastructure in life cycle analysis of hydrogen and electric systems applied to the Portuguese transportation sector. Int. J. Hydrogen Energy 2012, 37 (15), 10973-10985.

(74) IEA. Energy Policies of IEA Countries - Norway 2011 Review; International Energy Agency: Paris, FR, 2011. 


\section{ASSESSSME
EnVIrOHME
FUEL \& ELECTRICIY PRODUCTION}

VEHICLES (multiple technologies)
CHARGING INFRASTRUCTURES

FLEET

LARGE COVERAGE OF ENVIRONMENTALPMPACTS $\Rightarrow$ Plufe्t-haisechm

EVS DEPLOYMENT SCENARIOS (FUTURE)

LCA at

$\Rightarrow$ urban scale
Copenhagen 2016-2030

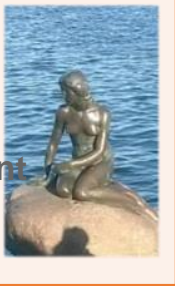

